\title{
CAPÍTULO 20: ESTIMATIVA DA PRODUÇÃO DE BIOGÁS PARA GERAÇÃO DE ENERGIA ELÉTRICA ATRAVÉS DE DEJETOS DE ANIMAIS DA PECUÁRIA NO BRASIL
}

\section{CAPÍTULO 20: PRODUCCIÓN ESTIMADA DE BIOGÁS PARA GENERACIÓN DE ELECTRICIDAD A TRAVÉS DE RESIDUOS ANIMALES GANADEROS EN BRASIL}

\author{
CHAPTER 20: ESTIMATED BIOGAS PRODUCTION FOR ELECTRICITY \\ GENERATION THROUGH LIVESTOCK ANIMAL WASTE IN BRAZIL
}

Fábio Ferreira Batista ${ }^{1}$; Milla Gomes Albuquerque ${ }^{2}$; Valmir Cristiano de Arruda Marques ${ }^{3}$; André Felipe de melo Sales Santos ${ }^{4}$

\section{RESUMO}

DOI: https://doi.org/10.31692/978-65-88970-19-5.298-316

O Brasil possui um grande potencial de incrementar e diversificar sua matriz elétrica mesmo esta já sendo de base significativa de energias renováveis. A participação da valorização energética de biomassas ainda é incipiente no país, mas as políticas de valorização energética e desenvolvimento de novas tecnologias estão mudando este cenário. Este trabalho objetivou avaliar o potencial de geração de energia elétrica a partir da valorização de dejetos da pecuária (bovinos, suinos, equinos e aves) através do uso do biogás gerado em sistemas anaeróbios. Foram utilizados dados secundários do tamanho dos rebanhos nacionais e literatura técnica para o cálculo dos potenciais. $\mathrm{O}$ cálculo do potencial teórico ainda considerou fatores relativos aos processos anaeróbios mais comuns e perdas do processo. Observou-se que o potencial de energia teórico seria de cerca de 36,3 TWh/ano, correspondendo 5,6\% do montante gerado pela matriz energética no ano avaliado (2019) e suficiente para atender de cerca de 18.658 .858 residências por um ano, equivalente à $25,7 \%$ das residências no Brasil, impactando diretamente na vida de cerca de 54,11 milhões de pessoas. Esse tipo de avaliação contribui para quebra de paradigmas neste tema em comparação a estudos em escala real. As contribuições reais seriam majoritariamente para a produção de energia distribuída com caráter de aumento da competitividade dos produtores locais e apelo sustentável aos seus empreendimentos.

Palavras-Chave: Dejetos da pecuária; Biogás; Energia Elétrica; Estimativa teórica.

\section{RESUMEN}

Brasil tiene un gran potencial para incrementar y diversificar su matriz eléctrica, aunque ya se basa en energías renovables. La participación en la recuperación energética de biomasa es aún incipiente en el país, pero a medida que las políticas de recuperación energética y el desarrollo de nuevas tecnologías están cambiando este escenario. Este trabajo tuvo como objetivo evaluar el potencial de generación de energía eléctrica a partir de la valorización de los desechos pecuarios (bovinos, porcinos, equinos y aves) mediante el uso de biogás generado en sistemas anaeróbicos. Se utilizaron datos secundarios sobre el tamaño de los rebaños nacionales y literatura técnica para calcular los potenciales. El cálculo del potencial teórico aún considera factores relacionados con los procesos anaeróbicos más comunes y las pérdidas del proceso. Se observó que el potencial energético teórico rondaría los 36,3 TWh/año, correspondiente al 5,6\% de la cantidad generada por la matriz energética en el año evaluado (2019) y

\footnotetext{
${ }^{1}$ Engenharia Ambiental, Universidade Federal Rural de Pernambuco, fabio19ferreira@gmail.com

${ }^{2}$ Engenharia Ambiental, Universidade Federal Rural de Pernambuco, engmillag@gmail.com

${ }^{3}$ Professor Doutor, Universidade Federal Rural de Pernambuco, valmir.arruda@ufrpe.br

${ }^{4}$ Professor Doutor, Universidade Federal Rural de Pernambuco, andrefelipe.santos@ufrpe.br
} 
suficiente para atender alrededor de 18.658 .858 residencias durante un año, equivalente al $25,7 \%$ de las residencias en Brasil, impactando directamente la vida de alrededor de 54,11 millones de personas. Este tipo de evaluación contribuye a romper paradigmas en este tema en comparación con estudios a escala real. Los aportes reales son principalmente para la producción de energía distribuida con el carácter de aumento de la producción local y atractivo sostenible para sus empresas.

Palabras clave: Residuos de ganado; Biogás; Energia electrica; Estimación teórica.

\begin{abstract}
Brazil has great potential to increase and diversify its electrical matrix, even though it is already based on renewable energies. The participation of the energy recovery of biomass is still incipient in the country, but as policies for energy recovery and the development of new technologies are changing this scenario. This work aimed to evaluate the potential of electric power generation from the valorization of livestock waste (cattle, swine, horses and birds) through the use of biogas generated in anaerobic systems. Secondary data on the size of national herds and technical literature were used to calculate the potentials. The calculation of the theoretical potential still considers factors related to the most common anaerobic processes and process losses. It was observed that the theoretical energy potential would be about $36.3 \mathrm{TWh} /$ year, corresponding to $5.6 \%$ of the amount generated by the energy matrix in the year evaluated (2019) and sufficient to serve around to $18,658,858$ residences for a year, equivalent to $25.7 \%$ of residences in Brazil, directly impacting the lives of approximately 54.11 million people. This evaluation contributes to breaking paradigms in this theme in comparison to studies on a real scale. The real contributions are mainly for the production of distributed energy with the character of increasing local production and sustainable appeal to its enterprises.
\end{abstract}

Key words: Livestock manure; Biogas; Electricity; Theoretical estimation.

\title{
INTRODUÇÃO
}

As atividades agropecuárias no Brasil têm sido ampliadas e com isso todas as atividades dos seus sistemas de produção. Assim, paralelamente a isso, tem-se aumentado significadamente a geração de dejetos dos animais envolvidos nessas atividades, que podem trazer prejuízos ambientais quando não conduzidos de forma adequada, como mau cheiro e contaminação da água, gerando um mal-estar ao bem-social também (AQUINO et. al., 2014). Segundo dados do IBGE (2019), o número de bovinos, suínos e galinhas giram em torno de 214 milhões, 41 milhões e 249 milhões, respectivamente. No Brasil, hoje, cerca de $19 \%$ de sua área total é ocupada por pastagens, o que equivale a aproximadamente 163 milhões de hectares (ABIEC, 2018). Com o setor agropecuário passando de um sistema de criação extensivo para um modelo intensivo de confinamento, reduzindo custos e aumentando a eficiência no processo, tem-se intensificado problemas ambientais, muito a partir da incorporação de mais volumes de dejetos de animais mais concentrados em um só local e mais próximo dos seres humanos (KUNZ e OLIVEIRA, 2006).

Vive-se uma crise quando se trata do meio ambiente. Todas as atividades humanas 
demandam energia, seja no trabalho, em casa, na rua, passeando ou se divertindo. (COLATTO e LANGER, 2011). Os problemas de mudanças climáticas pedem urgência quanto as suas resoluções, uma vez que a emissão dos gases de efeito estufa (GEE) está alterando as características físico-químicas da atmosfera, o que compromete o equilíbrio natural da biosfera e a qualidade de vida no planeta (SANTOS; JUNIOR, 2013). Desta forma, encontram-se possibilidades e alternativas para proporcionar um destino adequado à esses resíduos, de forma a proporcionar tratamentos eficientes e possíveis benefícios ambientais, sociais e econômicos, como a biodigestão anaeróbia, oferecendo mais uma fonte energética com custo reduzido (ZANATO, 2014). A contribuição de um sistema bioenérgetico é aproveitar todo potencial calorífico do gás metano $\left(\mathrm{CH}_{4}\right)$ presente na decomposição anaeróbia dos dejetos, potencial esse que pode chegar a 12.000 kcal por metro cúbico do biogás (SANTOS; JÚNIOR, 2013). Com a existência de uma alta procura por fontes de energias limpas, a bioenergia surge como uma alternativa viável para dar finalidade à esses dejetos agrícolas, uma vez que ela diminui a capacidade poluidora desses resíduos, pois o gás emitido por esses dejetos durante a sua decomposição é destinado à produção de energia agora e não mais ao meio ambiente e a porção sólida dos dejetos é utilizado como adubo orgânico (GASPAR, 2003). Além disso, Colatto e Langer (2011) promoveram estudos para o cálculo do potencial terórico de metano oriundos de dejetos animais.

Porém no Brasil ainda há baixos índices de tratamento de dejetos como da suinoculturo (LIMA; BONILLA; CÂMARA, 2020). Conhecendo as características dos dejetos de animais, os projetos e os sistemas de tratamentos ficam mais viáveis, além de contribuir para uma melhor avaliação dos impactos negativos que o manejo e as deposições inadequadas acarretariam (SOUZA et al., 2009).

Assim, partindo de uma análise relativa às informações qualitativas e quantitativas dos dejetos de animais no Brasil, objetivou-se avaliar o impacto positivo do aproveitamento energético desses dejetos na matriz elétrica nacional, destacando aspectos relativos ao manejo dos dejetos e possibilidades de ganhos econômicos, sociais e ambientais ao setor da pecuária nos relacionados a competitividade e sustentabilidade dos empreendimentos.

\section{FUNDAMENTAÇÃO TEÓRICA}




\section{Pecuária e geração de dejetos}

Os dejetos de origem animal são constituídos por fezes, urina, água desperdiçada pelos bebedouros e de higienização, resíduos de ração, pelos, lã, poeiras e outros materiais decorrentes do processo de criação (ZANATO, 2014).

Matos (2016) define que o esterco proveniente de animais, também conhecido como dejetos de animais, é um tipo de resíduo originado da pecuária e que necessita de um tratamento, podendo contaminar lençóis freáticos quando aplicados a lavoura sem o tratamento prévio.

Os dejetos animais se apresentam em grandes quantidades nas propriedades rurais criadoras de gados, aves, equinos e suínos, fornecendo matéria prima para a produção local de biogás (OJEDA et al., 2018).

Segundo Colatto e Langer (2011), pode-se observar a produção diária de biomassa animal associado ao quanto de dejeto é liberado por dia de acordo com determinado animal. $\mathrm{Na}$ Tabela 1 são apresentados os dados do efetivo de rebanhos, por tipo de rebanho e por região no Brasil, segundo (IBGE, 2019).

Tabela 1: Efetivo de rebanhos, por tipo de rebanho e por região no Brasil

\begin{tabular}{|c|c|c|c|c|c|c|c|c|c|c|}
\hline \multirow[b]{2}{*}{$\begin{array}{l}\text { Brasil, Grande } \\
\text { Região }\end{array}$} & \multicolumn{10}{|c|}{ Tipos de Animais (número de animais) } \\
\hline & Bovino & Bubalino & Equino & $\begin{array}{c}\text { Suíno - } \\
\text { total }\end{array}$ & $\begin{array}{c}\text { Suíno - matrizes } \\
\text { de suínos }\end{array}$ & Caprino & Ovino & $\begin{array}{c}\text { Galináceos } \\
\text { - total }\end{array}$ & $\begin{array}{c}\text { Galináceos - } \\
\text { galinhas }\end{array}$ & Codornas \\
\hline Norte & $\begin{array}{c}4,96 \mathrm{E}+0 \\
7\end{array}$ & $\begin{array}{c}9,52 \mathrm{E}+0 \\
5 \\
\end{array}$ & $\begin{array}{c}1,02 \mathrm{E}+0 \\
6 \\
\end{array}$ & $\begin{array}{c}1,50 \mathrm{E}+0 \\
6 \\
\end{array}$ & $3,43 \mathrm{E}+05$ & $\begin{array}{c}1,47 \mathrm{E}+0 \\
5 \\
\end{array}$ & $5,96 \mathrm{E}+05$ & $4,93 \mathrm{E}+07$ & $1,35 \mathrm{E}+07$ & $\begin{array}{c}1,74 \mathrm{E}+0 \\
5 \\
\end{array}$ \\
\hline Nordeste & $\begin{array}{c}2,86 \mathrm{E}+0 \\
7 \\
\end{array}$ & $\begin{array}{c}1,28 \mathrm{E}+0 \\
5 \\
\end{array}$ & $\begin{array}{c}1,34 \mathrm{E}+0 \\
6 \\
\end{array}$ & $\begin{array}{c}5,86 \mathrm{E}+0 \\
6 \\
\end{array}$ & $1,08 \mathrm{E}+06$ & $\begin{array}{c}1,07 \mathrm{E}+0 \\
7 \\
\end{array}$ & $1,35 \mathrm{E}+07$ & $1,83 \mathrm{E}+08$ & $4,83 \mathrm{E}+07$ & $\begin{array}{c}2,52 \mathrm{E}+0 \\
6\end{array}$ \\
\hline Sudeste & $\begin{array}{c}3,70 \mathrm{E}+0 \\
7 \\
\end{array}$ & $\begin{array}{c}1,99 \mathrm{E}+0 \\
5\end{array}$ & $\begin{array}{c}1,35 \mathrm{E}+0 \\
6\end{array}$ & $\begin{array}{c}6,99 \mathrm{E}+0 \\
6\end{array}$ & $7,07 \mathrm{E}+05$ & $\begin{array}{c}1,58 \mathrm{E}+0 \\
5\end{array}$ & $6,03 \mathrm{E}+05$ & $3,72 \mathrm{E}+08$ & $9,49 \mathrm{E}+07$ & $\begin{array}{c}1,11 \mathrm{E}+0 \\
7\end{array}$ \\
\hline Sul & $\begin{array}{c}2,54 \mathrm{E}+0 \\
7 \\
\end{array}$ & $\begin{array}{c}1,00 \mathrm{E}+0 \\
5 \\
\end{array}$ & $\begin{array}{c}9,34 \mathrm{E}+0 \\
5 \\
\end{array}$ & $\begin{array}{c}2,01 \mathrm{E}+0 \\
7 \\
\end{array}$ & $2,00 \mathrm{E}+06$ & $\begin{array}{c}2,07 \mathrm{E}+0 \\
5 \\
\end{array}$ & $3,96 \mathrm{E}+06$ & $6,74 \mathrm{E}+08$ & $6,08 \mathrm{E}+07$ & $\begin{array}{c}2,85 \mathrm{E}+0 \\
6 \\
\end{array}$ \\
\hline Centro-Oeste & $\begin{array}{c}7,43 \mathrm{E}+0 \\
7 \\
\end{array}$ & $\begin{array}{c}5,50 \mathrm{E}+0 \\
4 \\
\end{array}$ & $\begin{array}{c}1,20 \mathrm{E}+0 \\
6 \\
\end{array}$ & $\begin{array}{c}6,14 \mathrm{E}+0 \\
6 \\
\end{array}$ & $6,70 \mathrm{E}+05$ & $\begin{array}{c}1,02 \mathrm{E}+0 \\
5 \\
\end{array}$ & $1,05 \mathrm{E}+06$ & $1,87 \mathrm{E}+08$ & $3,15 \mathrm{E}+07$ & $\begin{array}{c}8,21 \mathrm{E}+0 \\
5 \\
\end{array}$ \\
\hline Brasil & $\begin{array}{c}2,15 \mathrm{E}+0 \\
8\end{array}$ & $\begin{array}{c}1,43 \mathrm{E}+0 \\
6 \\
\end{array}$ & $\begin{array}{c}5,85 \mathrm{E}+0 \\
6 \\
\end{array}$ & $\begin{array}{c}4,06 \mathrm{E}+0 \\
7 \\
\end{array}$ & $4,79 \mathrm{E}+06$ & $\begin{array}{c}1,13 \mathrm{E}+0 \\
7 \\
\end{array}$ & $1,97 \mathrm{E}+07$ & $1,47 \mathrm{E}+09$ & $2,49 \mathrm{E}+08$ & $\begin{array}{c}1,74 \mathrm{E}+0 \\
7 \\
\end{array}$ \\
\hline
\end{tabular}

Fonte: Adaptado de IBGE (2019)

Devido ao enorme potencial poluidor dos dejetos animais com a sua disposição inadequada, se faz necessário um sistema de tratamento que busque minimizar os impactos ambientais (SILVA et. al., 2015).

Na Figura 1 é apresentada a distribuição de bovinos por região do Brasil (IBGE, 2019). 
Figura 01: Distribuição de bovinos por região do Brasil

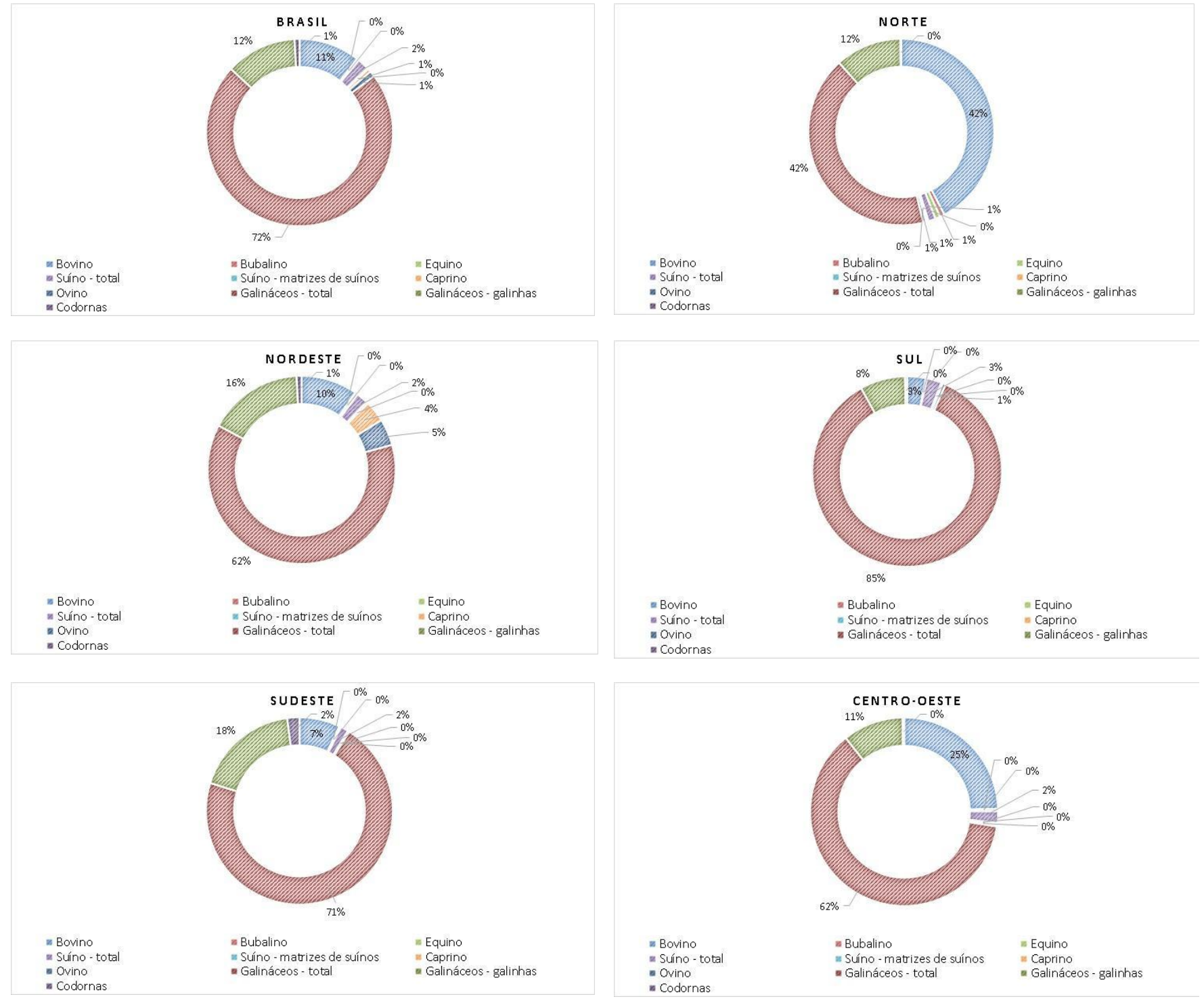

Fonte: Adaptado de IBGE (2019) 
Biodigestão anaeróbia

A biodigestão anaeróbia consiste em processo de degradação da matéria orgânica na ausência de oxigênio, produzindo uma mistura gasosa de metano $\left(\mathrm{CH}_{4}\right)$ e gás carbônico $\left(\mathrm{CO}_{2}\right)$, chamada de biogás, com alto potencial de aproveitamento energético por intermédio da queima e obtenção de energia térmica (SANTOS e JÚNIOR, 2013).

$\mathrm{Na}$ ausência total de oxigênio, a matéria orgânica será degradada a partir de colônias mistas de microrganismos que encontrarão perfeitas condições de proliferação (BLEY JR, 2015).

Segundo Júnior (2009), biodigestores são estruturas projetadas e construídas com o objetivo de produzir degradação da biomassa originada de residuos sem haver participação de oxigênio, gerando condições de degração da matéria orgânica mais acelerada de bactérias altamente consumidoras. De acordo com Motta (1986), tem-se como registro mais antigo de uso de biodigestores o ano de 1857, nas proximidades de Bombaim, na Índia, onde eram utilizados dejeto de equinos como afluente.

Segundo Kunz (2017) existem fatores que afetam a eficiência e a estabilidade da digestão anaeróbia os quais estão relacionados com as características do afluente e das condições internas do digestor. Dentre esses fatores pode-se citar o $\mathrm{pH}$ e o sistema tampão, uma vez que a atividade das bactérias responsáveis no processo dependem do $\mathrm{pH}$, além da dependencia de produção de ácidos orgânicos e da degradação desses compostos em metano. Alé disso, Kunz (2017) destaca o equilíbrio ácido-base presente, a temperatura, a homogeneização do substrato, a carga orgânica volumétrica, a inocuidade, o manejo e os agentes inibidores como fatores que também influenciam e afetam a estabilidade da digestão anaeróbia.

A utilização de biodigestores integram as atividades agropecuárias, uma vez que o resíduo agrícola de pouco valor comercial à primeira vista será reutilizado para fins que proporcionarão aumento na produção agrícola e energética (MATOS, 2016). Na França, a utilização de dejetos de animais tem-se intensificado nos trabalhos do setor de tratamento de resíduos orgânicos, incluindo a degradação anaeróbica, muito pois há um aumento na consciência ambiental nos países mais industrializados devido as limitações de demandas futuras de combustíveis fósseis, implicando na necessidade de desenvolvimento de energias renováveis (RIBEIRO et. al, 2020).

Os benefícios atribuídos aos biodigestores são grandes, preservando recursos locais, 
agregando valores econômicos nas propriedades e com uma produção acelerada de biogás, mirando uma autossuficiência em energia elétrica, agregando valor à propriedade rural e ao BIFPET produtor (COLATTO e LANGER, 2011).

A Figura 02 ilustra um sistema de biodigestão anaeróbico de dejetos de bovinos, aves, equinos e suínos.

Figura 02: Representação ilustrativa de aproveitamento energético de dejetos de animais.

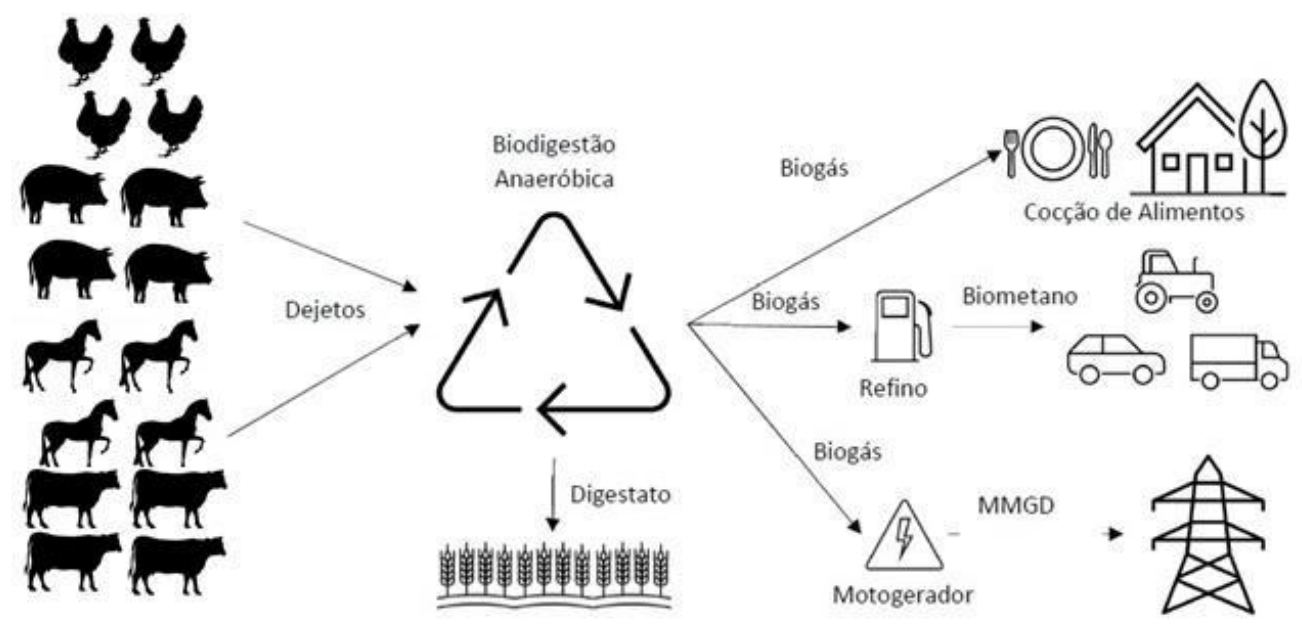

Legenda: MMGD: Micro e minigeração distribuída.

Fonte: Adaptado de EPE (2020)

\section{Biogás e metano}

Incidentalmente, foi a partir de uma demonstração da geração de gás por meio de uma mistura de estrume e água, feita por Louis Pasteur no século XIX, que o biogás, descoberto no século XVII, passou a ser considerado fonte de energia. Na década de 1940, a Índia começou a aproveitar, em plantas de geração de energia, o biogás oriundo de esterco de animais (GU et al., 2016). Biogás é composto pela mistura de gases, o metano $\left(\mathrm{CH}_{4}\right)$ consiste a $45-75 \%$ da 
mistura e o restante é de gás carbônico $\left(\mathrm{CO}_{2}\right)$ e outros gases, originados da decomposição anaeróbia da matéria orgânica (OJEDA et al., 2018). Segundo Kunz (2017), a composição típica do biogás é dada conforme a Tabela 2.

Tabela 2: Composição do biogás

$\begin{array}{cc}\text { Componente } & \text { Teor em volume \% } \\ \text { Metano } \mathrm{CH}_{4} & 50 \text { a } 75 \\ \text { Dióxido de Carbono }\left(\mathrm{CO}_{2}\right) & 25 \text { a } 40 \\ \text { Hidrogênio }\left(\mathrm{H}_{2}\right) & 1 \text { a } 3 \\ \text { Nitrogênio }\left(\mathrm{N}_{2}\right) & 0,5 \text { a } 2,5 \\ \text { Oxigênio }\left(\mathrm{O}_{2}\right) & 0,1 \text { a } 1 \\ \text { Gás Sulfídrico }\left(\mathrm{H}_{2} \mathrm{~S}\right) & 0,1 \text { a } 0,5 \\ \text { Amônio }\left(\mathrm{NH}_{3}\right) & 0,1 \text { a }, 05 \\ \text { Monóxido de carbono }(\mathrm{CO}) & 0 \text { a } 0,1 \\ \text { Água }\left(\mathrm{H}_{2} \mathrm{O}\right) & \text { Variável } \\ & \text { Fonte: Adaptado de Kunz }(2017) .\end{array}$

La Farge (1995) caracterizou o biogás quanto ao seu poder calorífico inferior, o qual representa o calor liberado pela combustão estando toda a água resultante no estado gasoso, em relação ao volume de metano concentrado conforme a Tabela 3.

Tabela 3: Poder calorífico do biogás a partir da concentração de metano presente.

$\begin{array}{cc}\mathbf{C H}_{\mathbf{4}} \% & \text { PCI (kWh/m } \\ 50 & 4,3 \\ 60 & 5,1 \\ 70 & 6,0 \\ 80 & 6,9 \\ 90 & 7,8 \\ 100 & 8,6\end{array}$

Fonte: Adaptado de La Farge (1995)

Ainda segundo La Farge (1995), o volume de metano a $0^{\circ} \mathrm{C}, 1 \mathrm{~atm}$ tem poder calorífico inferior de $9,94 \mathrm{kWh} / \mathrm{m}^{3}$ como característica média. Kunz et. al. (2014) trazem uma análise comparativa entre o biogás e outros combustíveis conforme a Tabela 4 onde é possível verificar que $1 \mathrm{~m}^{3}$ de biogás equivaleria a $1,428 \mathrm{kWh}$ segundo essa metodologia aplicada da fonte.

Tabela 4: Comparação entre o biogás e outros combistíveis

Combustíveis $1 \mathrm{~m}^{3}$ de biogás




$\begin{array}{cc}\text { Gasolina } & 0,613 \mathrm{~L} \\ \text { Querosene } & 0,579 \mathrm{~L} \\ \text { Óleo diesel } & 0,553 \mathrm{~L} \\ \text { Gás de cozinha (GLP) } & 0,454 \mathrm{~L} \\ \text { Lenha } & 1,536 \mathrm{~kg} \\ \text { Álcool hidratado } & 0,790 \mathrm{~L} \\ \text { Eletricidade } & 1,428 \mathrm{kWh}\end{array}$

Fonte: Adaptado de Gaspar (2003)

Ainda segundo Colatto e Langer (2011), o potencial de geração de energia é baseado na produção diária de biogás, o qual é considerado em termos teóricos que $1 \mathrm{~m}^{3}$ de biogás seria equivalente à $1,3 \mathrm{kWh}$, apoiando a ideia de geração de energia elétrica a partir do uso de biodigestores na degradação anaeróbia de dejetos orgânicos. O biogás ganha destaque por ser considerado uma fonte promissora de energia renovável pela sua abundância, principalmente no Brasil, e que podem trazer benefícios socioeconômicos e ambientais, propiciando destinações corretas aos dejetos, evitando contaminações do solo, lençóis freáticos, rios e açudes (VIEIRA et. al., 2019).

O biogás traz benefícios tanto ambientais como econômicos para o produtor rural, pode ser utilizado para a geração de eletricidade como também para a produção de calor (SUNADA et. al., 2012). O metano é um gás cujo efeito estufa estimado é em, no mínimo, 21 vezes a do $\mathrm{CO}_{2}$ (COLATTO e LANGER, 2011). O metano é um composto químico da classe dos hidrocarbonetos formado por um átomo de carbono e quatro átomos de hidrogênio, possuindo a fórmula molecular $\mathrm{CH}_{4}$, também chamado de gás natural quando sua concentração numa mistura gasosa é superior a 96\% em $\mathrm{CH}_{4}(\mathrm{BORGES}, 2020)$. Um meio viável para a sua formação é a queima de lixo orgânico e tem-se como uma das formas de destinação a sua utilização como fonte de energia elétrica (BORGES, 2020).

\section{Processos de biodigestão anaerobia usuais no Brasil}

Os processos de biodigestão anaeróbia mais usuais no Brasil são caracterizados por serem utilizados com biodigestores que atuam de forma contínua, ou seja, os dejetos a serem digeridos são colocados e, ao mesmo tempo, é feito o recolhimento do biogás, com o biodigestor podendo ser abastecido sempre por pequenas cargas de dejetos de forma diária ou semanal (DEGANUTTI et al., 2002). 
Com isso, segundo Lima (2021), pequisador e especialista em biogás, os modelos de biodigestores mais utilizados no Brasil são os do tipo lagoas cobertas, os quais são caracterizados por serem biodigestores escavados no solo, imperbeabilizados e recobertos com mantas plásticas, sendo normalmente PEAD ou PVC flexível. A sua adesão se dá por ser uma solução mais simples e de baixa inserção de tecnologias. Segundo Kunz (2017), o biodigestor do tipo lagoa coberta não precisa de sistema de aquecimento e nem de agitação de biomassa, porém, em contrapartida, apresenta baixa capacidade de geração de biogás, com variações entre 0,15 e $0,20 \mathrm{~m}^{3} \cdot \mathrm{kgVS}^{-1} \cdot \mathrm{d}^{-1}$. Ainda segundo Lima (2021), além desse modelo, existem processos de biodigestões anaeróbias recorrentes no Brasil que utilizam biodigestores mais industriais, como é o caso dos biodigestores de mistura completa os quais se caracterizam por serem normalmente construídos em tanques circular em concreto, acima do nível do solo, além de poderem operar com concentrações de sólidos que podem chegar a $40 \%$ por serem mais eficientes; também pode ser citado os biodigestores modelo fluxo tubular, conhecido também como fluxo pistão, definido por ser um reator de alimentação contínua e caracterizado como uma lagoa retangular coberta, permitindo que as partículas se locomovam na mesma sequência da direção em que elas entram no reator, com o material novo adcionado deslocando o mais antigo, fluindo como um pistão.

Kunz (2014) mostrou que a capacidade de geração de biogás dependerá do nível tecnológico do diferentes biodigestores conforme a Tabela 5.

Tabela 5: Capacidade de geração de biogás de reatores UASB e biodigestores para dejetos suínos

\begin{tabular}{|c|c|c|c|c|c|c|}
\hline $\begin{array}{l}\text { Geração de biogás } \\
\qquad\left(\mathrm{m}^{3} \cdot \mathrm{d}^{-1} \cdot \mathrm{m}^{-3)}\right.\end{array}$ & $\begin{array}{c}\mathrm{H}_{2} \mathrm{~S} \\
(\mathbf{p p m})\end{array}$ & $\begin{array}{l}\mathrm{CO}_{2} \\
(\%)\end{array}$ & $\begin{array}{l}\mathrm{CH}_{4} \\
(\%)\end{array}$ & $\begin{array}{c}\text { CMGB } \\
\left(\mathrm{m}^{3} \cdot \mathrm{kg} \mathrm{SV}^{-1}\right)\end{array}$ & $\begin{array}{c}\mathbf{B}_{0} \\
\left(\mathrm{~m}^{3} \cdot \mathrm{kg} \mathrm{SV}^{-1}\right)\end{array}$ & Tipo de reator (referência) \\
\hline 0,69 & 189 & 25 & 74 & 1,56 & 1,15 & $\begin{array}{l}\text { UASB escala piloto (COSTA, } \\
\text { 2007) }\end{array}$ \\
\hline 0,83 & 124 & 21 & 76 & 1,43 & 1,09 & $\begin{array}{c}\text { UASB (KUNZ e } \\
\text { ENCARNAÇÃO, 2007) }\end{array}$ \\
\hline 0,32 & 322 & 29 & 67 & 0,31 & 0,21 & BLC (KUNZ et. al., 2005) \\
\hline 0,21 & 536 & 34 & 62 & 0,33 & 0,20 & BLC (VIVAN e KUNZ, 2008) \\
\hline
\end{tabular}

Legenda: $\mathrm{BLC}=$ Biodigestor de lagoa coberta, $\mathrm{UASB}=$ Upflow Anaerobic Sludge Blanket, $\mathrm{CMGB}=$ Capacidade máxima de geração de biogás, B0=Capacidade máxima de produção de metano.

Fonte: Adaptado Kunz el al.(2014).

\section{Geração de energia elétrica com o uso do biogás}

Segundo Oliveira (2004), a geração de energia elétrica tendo o biogás como 
combustível pode ser dividida de acordo com as tecnologias a serem implementadas. Assim, inicialmente definiu o conjunto gerador de eletricidade, o qual é caracterizado por um motor de combustão interna Ciclo Otto adaptado para o uso de biogás como combustível e, além disso, ele é acoplado a um gerador de eletricidade, independendo assim do fornecimento da rede elétrica local para o seu funcionamento. Ainda segundo Oliveira (2004), tem-se o conjunto gerador economizador de eletricidade, o qual é caracterizado por um motor de combustão interna Ciclo Otto adaptado para o uso de biogás como combustível onde, além disso, está acoplado a um motor assíncrono, de dois ou quatro pólos, que passa a gerar energia ao ser conectado à rede de energia elétrica da concessionária local. Assim, a energia gerada é distribuída na propriedade e na rede externa até o transformador mais próximo.

Kunz e Oliveira, (2006) salientam que o rendimento, quando existe transformação da energia contida no biogás em elétrica, gira em torno de $25 \%$.

\section{METODOLOGIA}

A estimativa teórica da produção de metano foi realizada utilizando um dos métodos utilizáveis quando da necessidade de estimativas iniciais de produção de biogás através de determinação mais simplificada, mas baseada em dados obtidos em estudos em escala real.

Foi utilizada a metodologia de cálculo adaptada por Santos e Nardi Jr., 2013) que está sintetizada na Equação 1 e permite realizar este cálculo teórico do volume de metano. Nesta metodologia, são desconsiderados fatores tais como biodegradabilidade dos resíduos relacionados às suas características tais como estrutura química (percentagem de compostos ligno-celulósico ou recalcitrantes, por exemplo) e aspectos relacionados a toxicidade inerente aos próprios resíduos, variações ambientais de processo e operação. Desta feita seu resultado pode ser assumido como um maximo maximorum teórico ou valor máximo referencial para estimativas e posteriores correções que tornem os resultados mais próximos do potencial real.

$$
\mathrm{VCH}_{4}=\mathrm{N} \cdot \mathrm{T} \cdot \mathrm{Et} \cdot \mathrm{Pb} \cdot\left[\mathrm{CH}_{4}\right] \cdot \mathrm{VE} \mathrm{E}^{-1}
$$

Onde:

$\mathrm{VCH}_{4}$ : Volume de metano $\left(\mathrm{m}^{3}\right)$

$\mathrm{N}$ : número de animais do rebanho (unidade geradora)

T: tempo (dias)

Et: Esterco total $\left[\mathrm{kg}\right.$ dejeto. (dia. unidade geradora) $\left.{ }^{-1}\right]$ 
$\mathrm{Pb}$ : Produção de biogás [kg biogás.kg dejeto ${ }^{-1}$ ]

$\left[\mathrm{CH}_{4}\right]$ : Concentração de metano no biogás [\%]

$\mathrm{VE}^{-1}$ :Volume específico do metano $\left[\mathrm{kgCH}_{4} \cdot \mathrm{m}^{3} \mathrm{CH}_{4}\right]^{-1}$, igual a $0,670 \mathrm{kgCH}_{4}{ }^{-1} \cdot \mathrm{m}^{-3} \cdot \mathrm{CH}_{4}$

Para o cálculo do número de cabeças utilizou-se os dados compilados por tipo de animal avaliado neste estudo a partir dos dados obtidos pelo censo do IBGE (2019) em que há a representação do quantitativo total do efetivo de rebanhos apresentado na Tabela 1. Foram somados os totais por regiões dos rebanhos de suínos, bovinos, equinos e aves (galináceos totais + codornas). Para o cálculo do Et, $\mathrm{Pb}$ e concentração do biogás (\%) por diferentes tipos de resíduos utilizou-se os dados da Tabela 6 (COLATTO e LANGER, 2011). Foi considerado geração de metano anualizada ( $\mathrm{T}=365$ dias $)$.

Tabela 6: Valores de Conversão energética para alguns resíduos orgânicos animais (dejetos)

\begin{tabular}{c|c|c|c}
\hline $\begin{array}{c}\text { Origem do } \\
\text { material }\end{array}$ & $\begin{array}{c}\text { Kg de dejeto } \\
\text { (dia. unidade geradora) }^{-1} \mathbf{( E t )}\end{array}$ & $\begin{array}{c}\text { Kg de biogás. } \\
\text { Kg de dejeto }^{-1} \mathbf{( P b )}\end{array}$ & $\begin{array}{c}\text { Metano } \\
(\mathbf{\%})\left[\mathbf{C H}_{4}\right]\end{array}$ \\
\hline Suíno & 2,25 & 0,062 & $66 \%$ \\
\hline Bovinos & 10 & 0,037 & $60 \%$ \\
\hline Equinos & 12 & 0,048 & $60 \%$ \\
\hline Aves & 0,18 & 0,055 & $60 \%$ \\
\hline
\end{tabular}

Fonte: Adaptado por Colatto e Langer (2012)

A partir do recolhimento dos volumes teóricos de dados, estimou-se o potencial de energia elétrica que pode ser convertido a partir do metano em função do seu poder calorífico inferior (PCI) na faixa de 50 a 70\%, de acordo com a Tabela 3 (LA FARGE, 1995).

Foi também considerado um fator de correção de 0,25 (25\%), segundo o destacado por Kunz e Oliveira (2006) devido ao baixo rendimento da transformação energética de biogás em energia elétrica com um conjunto de motogeradores de eletricidade. Na Equação 2 apresenta-se a expressão do cálculo do Potencial médio de conversão de biogás em energia elétrica corrigido.

Onde:

$$
\text { PotmédioCH4 }=\left[\frac{P C I 50 \%+P C I 70 \%}{2}\right] .0,25(E q .2)
$$

PCI50\%: poder calorífico inferior do biogás com volume de metano a 50\% $(\mathrm{kWh})$ PCI70\%: poder calorífico inferior do biogás com volume de metano a 70\% $(\mathrm{kWh})$

A quantificação do biogás foi feita de acordo com a Equação 3, utilizando os percentuais de metano tipicos obtidos na digestão anaeróbia de cada tipo de dejeto animal 
(Tabela 6). Além disso, foi considerado um fator de correção de 0,5 (50\%) da produção de biogás em função do processo, juntamente com as perdas recorrentes de biodigestão no uso de biodigestores mais simples (biodigestores convencionais, lagoas cobertas), para a quantificação do volume de biogás real de acordo com a Equação 4.

$\frac{\text { Vbiogás }=\mathrm{VCH}_{4}}{\text { Metano }}(\%)(E q .3)$

Vbiogásreal $=$ Vbiogásteórico. $f c(E q .4)$

Onde:

$f_{c}=$ fator de correção referente a eficiência média dos processos de biodigestão mais usuais na produção de biogás para resíduos animais e perdas na produção $(0,5$, ou seja $50 \%)$

Para o cálculo do montante de energia elétrica em $\mathrm{kWh}$ foram utilizandos os resultados associdos obtidos pelas Equações 2 e 4, substituidos na Equação 5.

Energia $(k W h)=$ Vbiogásreal $*$ PotmedioCH4(Eq. 5)

\section{RESULTADOS E DISCUSSÃO}

Para o cálculo do potencial de geração de energia elétrica a partir dos principais resíduos gerados pela pecuária no ano de 2019 inicialmente procedeu-se com o cálculo do fator de conversão de biogás em energia elétrica apartir da Equação 2. O valor obtido foi de foi 1,290 kWh.m³ biogás. Este valor esteve próximo do obtido por Gaspar (2003), de 1,428 kWh.m ${ }^{3}$ biogás (Tabela 4). Na Tabela 7 são apresentados os dados síntese anuais da geração de resíduos, volumes de metano e biogás corrigidos e potencial teórico de geração de energia elétrica obtidos através das Equações 1, 2 e 4.

Tabela 7: Quantidade de resíduos, volume de metano, biogás, biogás corrigido e quivalente em energia elétrica

\begin{tabular}{l|c|c|c|c}
\hline & Bovino & Equínos & Suíno & Aves \\
\hline Quantidade de resíduos gerado (t/ano) & $7,84 \mathrm{E}+08$ & $2,56 \mathrm{E}+07$ & $3,33 \mathrm{E}+07$ & $9,75 \mathrm{E}+07$ \\
\hline
\end{tabular}




\begin{tabular}{l|c|c|c|c}
\hline Vmetano (m³/ano) & $2,60 \mathrm{E}+10$ & $1,10 \mathrm{E}+09$ & $2,03 \mathrm{E}+09$ & $4,80 \mathrm{E}+09$ \\
\hline Vbiogás $\left(\mathrm{m}^{3} /\right.$ ano) & $4,33 \mathrm{E}+10$ & $1,84 \mathrm{E}+09$ & $3,08 \mathrm{E}+09$ & $8,00 \mathrm{E}+09$ \\
\hline $\begin{array}{l}\text { Vbiogás corrigido em função do } \\
\text { processo (m/ano) }\end{array}$ & $2,17 \mathrm{E}+10$ & $9,18 \mathrm{E}+08$ & $1,54 \mathrm{E}+09$ & $4,00 \mathrm{E}+09$ \\
\hline $\begin{array}{l}\text { Equivalente em energia elétrica } \\
\text { kWh/ano) }\end{array}$ & $2,79 \mathrm{E}+10$ & $1,18 \mathrm{E}+09$ & $1,99 \mathrm{E}+09$ & $5,16 \mathrm{E}+09$ \\
\hline TOTAL (kWh/ano) & $3,63 \mathrm{E}+10$ & & & \\
\hline TOTAL (TWh/ano) & $\mathbf{3 6 , 3}$ & & & \\
\hline
\end{tabular}

Fonte: Própria (2021)

Na Figura 03 apresenta-se a participação (percentual) dos diferentes rebanhos no potencial energético de geração de energia teórico pelos principais resíduos da pecuária.

Figura 03: Participação dos diferentes rebanhos percentualamente no potencial energético de geração de energia pelos principais resíduos da pecuária

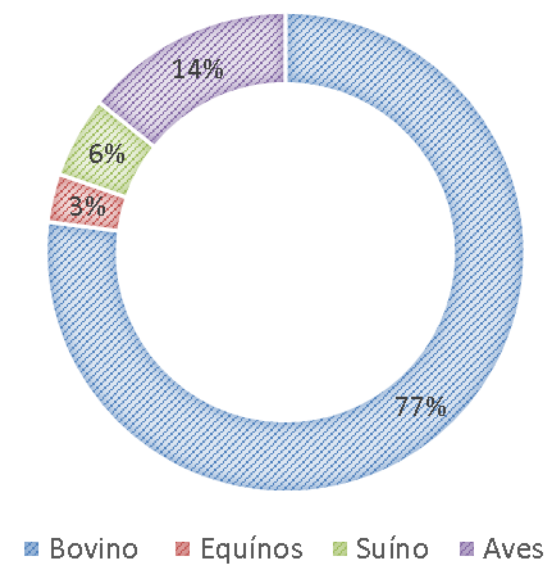

Fonte: Própria (2021)

Observou-se através do cálculo da energia eletrica potencial teórica total que seria possível gerar através unicamente dos resíduos da pecuária em 2019 cerca de 36,3 TWh.

Segundo dados do Balanço Energético Nacional 2020 (Relatório Síntese/Ano Base 2019) a oferta Interna de energia elétrica teve um avanço de 2,3\% em 2019 em relação a 2018, alcançando 651,3 TWh (BEN, 2020).

A contribuição na matriz elétrica do setor seria de cerca de 5,6\% somente com o aproveitamento energético dessse resíduo. Em relação ao ano de 2018 o aproveitamento desses resíduos seria capaz de suprir todo aumento da demanda verificada de 2018 para 2019 $(2,3 \%)$.

De acordo com o que define Resenha Mensal do Mercado de Energia Elétrica (2020), 
o consumo nas residências brasileiras foi de $162 \mathrm{kWh} /$ mês para o consumidor médio, o que corresponde a cerca de $1.944 \mathrm{kWh} /$ ano. Desta forma considerando apenas a contribuição desse potencial de $36,3 \mathrm{TWh} /$ ano calculado teríamos a possibilidade de prover de energia a cerca de 18.658 .858 residências por um ano.

O Brasil tornou-se um dos maiores produtores mundiais de gado bovino, suíno e de frangos. Em 2016, a área total de pastagens no país ocupava 230 milhões de hectares. Essa atividade produz dejetos e outros resíduos da produção cujo descarte representa fonte de poluição do solo e de recursos hídricos, bem como de emissão de gás metano (não tratado) na atmosfera.

Apesar da maior contribuição observado neste cálculo teórico proporcionalmente ter sido para os resíduos de bovinos (77\%) e aves (14\%) (Figura 03), há particularidades no manejo desses resíduos que devem ser observados. A criação de gado bovino, no Brasil, é majoritariamente, de forma extensiva, o que dificulta a coleta de seus resíduos (ABIOGÁS, 2016). Em relação aos resíduos avícolas esse é um segmento que ainda apresenta potencial restrito para a produção do biogás devido dois fatores. O primeiro é devido estes os dejetos coletados por meio da "cama de frango", são mais secos do que o ideal para seu aproveitamento na produção de biogás. O segundo é que a "cama de frango" tem outros destinos economicamente lucrativos, como, por exemplo, a venda diretamente para a fabricação de fertilizante (nitrogênio), o que pode encarecer a sua utilização como matéria-prima para o biogás.

A suinocultura por sua vez, vem se destacando nos últimos 20 anos e concentra praticamente toda a produção de biogás de origem pecuária no Brasil, apesar de, também, ainda ser diminuta.

Segundo a (ABISOLO, 2016) a suinocultura produziu, em 2015, $196 \mathrm{mil} \mathrm{Nm}^{3} / \mathrm{dia}$, o que representou $14 \%$ do total produzido no país, para um potencial de produção de cerca de $123 \mathrm{mil} \mathrm{Nm}^{3} /$ dia. A pecuária suína utiliza água de forma intensiva, o que significa, ao mesmo tempo, um elevado custo ambiental para o processo de extração de sua carne e um custo relativamente baixo para a produção do biogás, dada a facilidade de sua coleta. A esse respeito, deve ser observada a escala produtiva (USDA, 2017).

Em relação aos rejeitos dos equinos não há dados apreciáveis e poucos estudos do seu potencial aproveitamento para biogás. Geralmente estes resíduos são compostados, incorporados ao solo no próprio empreendimento ou vendidos a terceiros. 
A matriz elétrica brasileira é composta de $64,9 \%$ de energia hidráulica, tendo apenas $8,4 \%$ da oferta de energia vinda da biomassa (BEN, 2020). Há um enorme potencial de contribuição de melhor aproveitamento desses resíduos para garantir sustentabilidade e competitividade ao setor pecuário.

Mesmo com as limitações observadas deve-se destacar que a grande contribuição do melhor aproveitamento desses resíduos seria para a geração distribuída, para diversificação da matriz elétrica e nas contribuições ao meio ambiente da valorização e destinação mais adequada desses resíduos, com ganhos para os produtores localmente e a possivel utilização, a depender da escala do plantel, para geração de calor ou produção de energia a partir do biogás.

\section{CONCLUSÕES}

Segundo a metodologia utilizada, a contribuição para a produção de energia elétrica através da biodigestão anaeróbia de rejeitos dos principais rebanhos da pecuária no Brasil seria de cerca de cerca de 5,6\% em relação ao montante gerado pela da matriz energética no ano de 2019 e equivalente a uma contribuição equivalente para uma população de cerca de 18.658.858 residências por um ano, o que segundo a PNAD (2019) e o IBGE (2020) corresponde à aproximadamente 25,7\% das residências particulares do Brasil, oferecendo energia elétrica a cerca de 54,11 milhões de pessoas.

. Apesar das dificildades logísticas e operacionais para os rejeitos de bonivos e os limitantes econômicos e técnicos para os rejeitos avícolas, essa é uma alternativa factível e economicamente interessante para os pecuaristas e incentivos como os que se percebe, no caso dos rejeitos da suinocultura, seriam uma grande contribuição para a produção de energia distribuida com caráter de aumento da competitividade dos produtores locais, fechamento do ciclo produtivo e apelo sustentável aos seus empreendimentos.

\section{REFERÊNCIAS}

ABIEC. Evolução da área de pastagem e produtividade da pecuária de corte. 2018. Disponível em < http://abiec.com.br/sustentabilidade/>. Acesso em: 11/04/2021. 
Disponível em: <http://abisolo.com.br/anuario-edicoes-anteriores/>. Acesso em: 11/04/21.

ALMEIDA, C. Potencial de produção de biogás a partir de biomassa de suinocultura com culturas energéticas. 2016. 97f. Dissertação (Mestrado). Universidade Estadual do Oeste do Paraná. Programa de pós-graduação em Engenharia de Energia e Agricultura - Cascavel, 2016.

AQUINO, G.T.; BRONDANI, F.M.M.; SOUZA, R.A.A.; GERON, V.L.M.G. O uso do biogás no âmbito rural como proposta de desenvolvimento sustentável. Revista Científica da Faculdade de Educação e Meio Ambiente, v.5, n.1, p. 140-149, 2014.

BARSANO, Paulo Roberto; BARBOSA, Rildo Pereira. Meio ambiente: Guia prático e didático. São Paulo. $2^{\mathrm{a}}$ Edição 2017. Editora Saraiva.

BLEY JR, C. Biogás: a energia invisível. 2. ed. Foz do Iguaçu, PR: ITAIPU, 2015.

BORGES, Dayane. Metano, o que é? Definição, características, formação e efeito estufa.

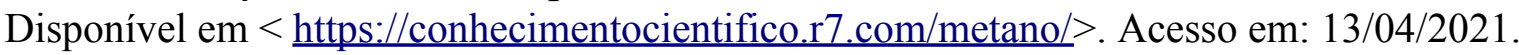

BRASIL, Ministério de Minas e Energia, 2020. BEN: Balanço Energético Nacional. Empresa de Pesquisa Energética. Disponível em: $<$ https://www.epe.gov.br/pt/publicacoes-dados-abertos/publicacoes/balanco-energetico-nacion al-2020>. Acesso em: 26/04/2021.

BRASIL, Ministério de Minas e Energia, 2020. Resenha Mensal do Mercado de Energia Elétrica. Empresa de pesquisa energética. Ano XIII, Número 148, Janeiro de 2020. Disponível

em: $<\underline{\text { https://www.epe.gov.br/sites-pt/publicacoes-dados-abertos/publicacoes/PublicacoesArquivos }}$ /publicacao-153/topico-510/Resenha\%20Mensal\%20-\%20Janeiro\%202020 v4.pdf> Acesso em: 26/04/2021.

BRASIL, Ministério de Minas e Energia, 2020. Recursos energéticos distribuídos: potencial técnico do metano da pecuária bovina. . Empresa de Pesquisa Energética. Disponível em: $<\underline{\text { https://www.epe.gov.br/sites-pt/publicacoes-dados-abertos/publicacoes/PublicacoesArquivos }}$ /publicacao-543/EPE-DEA-NT-013-2020\%20-\%20RED\%20Potencial $\% 20$ Pecu $\% \mathrm{C} 3 \%$ A1ria \%20Bovina.pdf $>$. Acesso em: 28/04/2021.

COSTA, C. C. Avaliação de sistema anaeróbio (RAC-UASB) no tratamento de água residuária de suinocultura e aplicação via fertirrigação, em feijão-vagem cultivado em ambiente protegido. 2007. 173f. Tese (Doutorado em Engenharia de Água e Solo) Universidade Federal de Lavras, Lavras.

DEGANUTTI, R.; PALHACI, M. C. J. P.; ROSSI, M.; TAVARES, R; SANTOS, C. Biodigestores rurais: modelos indiano, chinês e batelada. 2002 Disponível em: $<$ https://www.agencia.cnptia.embrapa.br/Repositorio/Biodigestores $000 \mathrm{~g} 76 \mathrm{qdzev} 02 \mathrm{wx} 5 \mathrm{ok} 0 \mathrm{w}$ tedt3spdi71p.pdf $>$. Acesso em: 26/04/2021.

GASPAR, R. Utilização de biodigestores em pequenas e médias propriedades rurais com ênfase na agregação de valor: um estudo de caso na região de Toledo-PR. 2003. 
GU, L. et al. Where is the future of China's biogas? Review, forecast, and policy implications. Petroleum Science, v. 13, p. 604-624, 2016. Disponível em: <https:// link.springer.com/article/10.1007/s12182-016-0105-6>. Acesso em: 25/04/2021.

IBGE. Efetivo dos rebanhos, por tipo de reganho, segundo o Brasil, as grandes regiões e as unidades da federação. $2019 . \quad$ Disponível em $<$ https://www.ibge.gov.br/estatisticas/economicas/agricultura-e-pecuaria/9107-producao-da-pe cuaria-municipal.html?=\&t=resultados$>$. Acesso em: 09/04/2021.

IBGE. IBGE estima população do país em 211,8 milhões de habitants. 2020. Disponível em:

$<\underline{\text { https://censo2021.ibge.gov.br/2012-agencia-de-noticias/noticias/28676-ibge-estima-populac }}$ ao-do-pais-em-211-8-milhoes-de-habitantes.html\#: :text=IBGE $\% 20$ estima $\% 20$ popula $\% \mathrm{C} 3 \%$ A7\%C3\%A3o $\% 20 \mathrm{do} \% 20 \mathrm{pa} \% \mathrm{C} 3 \% \mathrm{ADs} \% 20 \mathrm{em} \% 20211 \% 2 \mathrm{C} 8 \% 20 \mathrm{milh} \% \mathrm{C} 3 \% \mathrm{~B} 5 \mathrm{es} \% 20 \mathrm{de} \% 2$ Ohabitantes,-Editoria\%3A\%20Estatisticas\%20Sociais $>$. Acesso em: 13/05/2021.

JÚNIOR, B. C. Embrapa - Agroenergia da biomassa residual: perspectivas energéticas, socioeconômicas e ambientais. 2. ed. Foz do Iguaçu: FAO. 2009.

KUNZ, A. Embrapa - Curso: Energias renováveis processos de biodigestão. 2017. Concórdia: Embrapa.

Disponível

em:

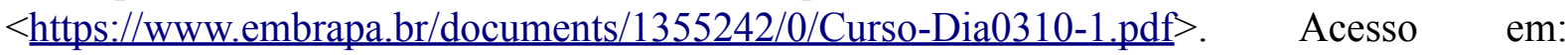

25/04/2021.

KUNZ, A.; ENCARNAÇÃO, R. Tratamento de dejetos de animais . In: GEBLER, L.;PALHARES, J. C. P. (Ed.). Gestão na agropecuária. Brasília, DF: Embrapa. Informação Tecnológica, 2007. P. 169-191.

KUNZ, A.; OLIVEIRA, P. A. V.; HIGARASHI. M. M. Biodigestor para o tratamento de dejetos suínos: influência da temperatura ambiente. Concórdia: Embrapa Suínos e Aves, 2005. 5 p. (Embrapa Suínos e Aves. Comunicado técnico, 416).

KUnZ, A.; OLIVEIRA, P. A. V.; HIGARASHI. M. M. Embrapa - Gestão Ambiental na Agropecuária. 2014. V. 2, Cap. 6, p. 236-281.

KUNZ A., OLIVEIRA P. A. V. de. Aproveitamento de dejetos de animais para geração de biogás. Revista de Política Agrícola. Nº 3, p28-35, 2006.

LA FARGE, B. de. Le biogaz: procédés de fermentation méthanique. Paris: Masson, 1995.

LIMA, H. Q. de. Biodigestor: modelos e configurações. 2021. Disponível em:

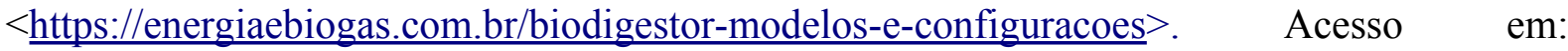
26/04/2021.

MATOS, Camila Ferreira. Produção de biogás e biofertilizante a partir de dejetos de bovinos, sob sistema orgânico e convencional de produção. 2016. 52f. Dissertação (Mestrado em Engenharia Agrícola e Ambiental). Instituto de Tecnologia, Departamento de Engenharia, Universidade Federal Rural do Rio de Janeiro, Seropédica, RJ, 2016. 
MOTTA, F. S. da; Produza sua energia: biodigestores anaeróbios. Recife: SETE, 1986.

OJEDA, L.; VASCONCELLOS, L. M.; SILVA, S. N.; Projeto de um biodigestor de dejetos de gado leiteiro para uma pequena propriedade rural. Anais do $10^{\circ}$ SALÃO INTERNACIONAL DE ENSINO, PESQUISA E EXTENSÃO - SIEPE. Universidade Federal do Pampa. Santana do Livramento, 6 a 8 de novembro de 2018.

PNAD. Pesquisa nacional por amostra de domicílios. 2019. Disponível em:

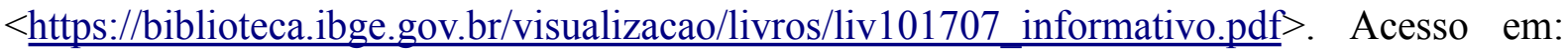
12/05/2021.

OLIVEIRA, P. A. V. de. Produção e aproveitamento do biogás. In: OLIVEIRA, P. A. V. de. Tecnologias para o manejo de resíduos na produção de suínos: manual de boas práticas. Concórdia: Embrapa Suínos e Aves, 2004. Cap. 4, p.43-55.

RIBEIRO, T.; CRESSON, R.; POMMIER, S.; PREYS, S.; ANDRÉ, L.; BÉLINE, F.; BOUCHEZ, T.; BOUGRIER, C.; BUFFIÈRE, P.; CACHO, J. et. al.; Measurement of Biochemical Methane Potential of Heterogeneous Solid Substrates: Results of a Two- Phase French Inter-Laboratory Study. Water 2020, 12, 2814. DOI:10.3390/w12102814

SANTOS, E. L. B. D.; NARDI JUNIOR, G. Produção de biogás a partir de dejetos de origem animal. Tekhne e Logos, Botucatu, SP, v.4, n.2, agosto, 2013.

SILVA, J. L G.; SILVA, A. C. C.; MITO, J. Y. L.; VENDRAME, M. G.; NASCIMENTO, K. R.; MENDES, I. S. Estimativa do potencial de produção de biogás no Brasil a partir de dejetos suínos. IV Simpósio Internacional sobre Gerenciamento de Resíduos Agropecuários e Agroindustriais. 05 a 07 de maio de 2015. Rio de Janeiro, RJ. 2015.

SOUZA, C. F.; SIQUEIRA C., CÍNARA C.; CAMPOS, J. A.; TEIXEIRA M., A.; PINTO M. F., W. Caracterização de dejetos de suínos em fase de terminação. Revista Ceres, vol. 56, núm. 2, 2009, p. 128-133. Universidade Federal de Viçosa. Viçosa, Brasil.

SUNADA, N. S.; ORRICO, A. C. A.; ORRICO JR, M. A. P.; VARGAS JR, F. M.; GARCIA, R. G.; FERNANDES, A. R. M. Potential of biogás and methane production from anaerobic digestion of poultry slaughterhouse effluent. Revista Brasileira de Zootecnica, Viçosa, v. 41, n. 11, p. 2379-2383, 2012.

USDA - UNITED STATES DEPARTMENT OF AGRICULTURE. Foreign Agricultural Service. Livestock and poultry: world markets and trade. Out. 2017. Disponível em: $<$ http://usda.mannlib.cornell.edu/MannUsda/ viewDocumentInfo.do?documentID=1488 $>$. Acesso em: 21/04/21.

VIEIRA, F. P.; DOMINGUES, E. G.; RAMALHO, S. S.; PINTO, L. S.; NETO, D. P. Análise de viabilidade econômica do aproveitamento energético do biogás e do biometano provenientes de dejetos suínos: estudo de caso. Tecnia, v.4, n.1, 2019, p. 146-167. Instituto Federal de Goiás 


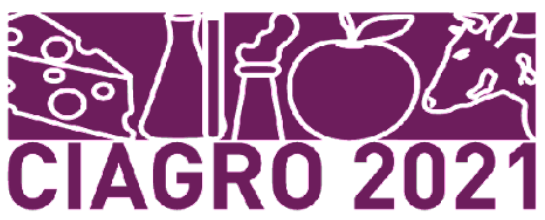

VIVAN, M.; KUNZ, A. Purificação de biogás em meio suporte sólido. In: Seminário DE DESENVOLVIMENTO DE PESQUISA, 12., 2008, Concórdia, Anais ...Concórdia: Proser SEDEPE, 2008.

ZANATO, J.A.F. Produção e Qualidade do Biogás Gerado com os Dejetos de Diferentes Espécies de Animais. São Paulo. Dissertação (doutorado) - Universidade Federal de Educação e Tecnologia de Goiás. 